\title{
Ormeloxifene versus combined oral contraceptive pills to control blood loss in cases of dysfunctional uterine bleeding
}

\author{
Ankita Gupta ${ }^{1}$, Rishika Raj ${ }^{2 *}$ \\ ${ }^{1}$ Department of Obstetrics and Gynecology, Shri Ram Murti Smarak Institute of Medical Sciences, Bareilly, Uttar \\ Pradesh, India \\ ${ }^{2}$ Department of Obstetrics and Gynaecology, Mayo Institute of Medical College, Barabanki, Uttar Pradesh, India \\ Received: 26 August 2019 \\ Accepted: 30 September 2019 \\ *Correspondence: \\ Dr. Rishika Raj, \\ E-mail: dr.rishikasrivastava14@gmail.com \\ Copyright: (c) the author(s), publisher and licensee Medip Academy. This is an open-access article distributed under \\ the terms of the Creative Commons Attribution Non-Commercial License, which permits unrestricted non-commercial \\ use, distribution, and reproduction in any medium, provided the original work is properly cited.
}

\begin{abstract}
Background: Dysfunctional uterine bleeding is one of the most often encountered gynecologic problems causing anemia, reduced quality of life and unnecessary hysterectomies. A prospective study was conducted on women with DUB to study the effect of ormeloxifene versus combined oral contraceptive pills in controlling blood loss in them.

Methods: 100 Women with DUB were enrolled randomly in three groups. After baseline assessment each patient in group A was treated with iron tablets, containing $100 \mathrm{mg}$ elemental iron and folic acid $1.5 \mathrm{mg}$, for three months and were termed as control group. Group B patients were treated with ormeloxifene in dose of $60 \mathrm{mg}$ twice a week for twelve weeks. Group C patients were treated with combined oral contraceptive pills for twenty- one days starting from third day of their LMP. The treatment was continued for three consecutive cycles. The efficacy of the studied drugs was analyzed by comparing the baseline and post treatment PBAC score, haemoglobin level and endometrial thickness, using appropriate statistical tests.

Results: Ormeloxifene was more effective than only iron or combined oral contraceptive therapy in controlling menstrual blood loss $(79.11 \%$ versus $58.57 \%)$. There was a reduction in endometrial thickness in group receiving ormeloxifene as well as in the group receiving combined oral contraceptive pills $(\mathrm{p}=0.486)$, however this was statistically not significant.

Conclusions: Ormeloxifene was significantly better than combined OCP in reduction of menstrual blood flow in cases of DUB. It has better compliance and marked improvement in subjective symptoms as compared to OCP.
\end{abstract}

Keywords: Centchroman, Combined oral contraceptive pills, Dysfunctional uterine bleeding, Ormeloxifene, Pictorial Blood loss assessment chart, Selective estrogen receptor modulators

\section{INTRODUCTION}

DUB is defined as abnormal, irregular bleeding (excessively heavy, prolonged, or at frequent intervals of bleeding) in the absence of demonstrable pelvic disease, complications of pregnancy or systemic disease..$^{1-4}$ The exact mechanism is uncertain but is thought to be caused by dysfunction of hypothalamic-pituitary-ovarian axis Livingstone $\mathrm{M}$ et al. ${ }^{5}$ Dysfunctional uterine bleeding is the diagnosis in $40-60 \%$ of women with excessive menstrual bleeding which is more than $80 \mathrm{~mL}$ blood loss (normal menstrual loss $<80 \mathrm{~mL}$ ). Heavy menstrual bleeding may affect a woman's health both medically and socially, causing problems such as iron deficiency anaemia and social phobia respectively.

In developing countries like India, about $20 \%$ of DUB cases are seen among adolescent and $40 \%$ among women 
above 40 years Patel SR et al. ${ }^{6}$ Approximately $90 \%$ of DUB results from anovulatory and $10 \%$ occur with ovulatory cycles Sonoda Y et al. ${ }^{7}$

Medical management of menorrhagia is a challenging task and wide variations in the available drugs prescribed for this condition show a lack of consensus for medical treatment. Need of the hour for the treatment of DUB should be a designer drug which blocks the action of oestrogen on endometrium but not its beneficial actions on other tissues. Ormeloxifene also known as centchroman is one such drug, categorized as "selective oestrogen receptor modulator".

\section{METHODS}

The present study was undertaken between August 2011 and April 2012.

Out of total of 450 cases of abnormal uterine bleeding, 225 registered patients during this period were found to have DUB. Out of them only 100 patients consented for drug trial study were included in the present comparative drug trial.

\section{Inclusion criteria}

- Women between menarche till menopause

- AUB cases having no evidence of pelvic pathology on clinical examination or USG

- No hormonal therapy taken within 3 months

- No IUCD used or removed within last 6 months

- Negative cervical cytology and colposcopy examination.

\section{Exclusion criteria}

- Any systemic diseases such as platelet disorder or coagulopathy, previous history of thrombosis, history of migraine

- Pregnancy induced bleeding disorders like abortion, ectopic pregnancy

- Increased bleeding due to IUCDS

- Pelvic pathologies- such as malignancies of uterus/cervix/ovary/vagina

- Consistent use of oral contraceptives

- Hypersensitivity to the drug

- $\quad$ Post- menopausal bleeding

- History of breast malignancy, palpable tumour, suspected adenomyosis, current genital infection

- Associated infertility

- Active bleeding necessitating emergency treatment

- Patients with severe anaemia $(\mathrm{Hb}<6$ gm \%).

Out of 450 patients of abnormal uterine bleeding, 100 patients of dysfunctional uterine bleeding who consented for drug trial study, were included in the study and were divided into following three groups:

\section{Group A (Iron therapy group)}

Comprised of the patients of DUB (34 patients) who were treated by prescribing only iron tablets containing $100 \mathrm{mg}$ elemental iron and folic acid $1.5 \mathrm{mg}$, for three months and were termed as control group.

\section{Group B (Ormeloxifene group)}

Comprised of patients of DUB (33 patients) who were treated by prescribing ormeloxifene in dose of $60 \mathrm{mg}$ twice a week for twelve weeks.

The efficacy of ormeloxifene, subjective and objective findings of improvement in condition of patients, tolerance of drug and side effects etc. were noted.

\section{Group C (Combined oral contraceptive group)}

Comprised of patients of DUB (33 patients) who were treated with combined oral contraceptive pills for twentyone days starting from third day of their LMP. This treatment was continued for three consecutive cycles.

The efficacy of combined OCPs, subjective and objective findings of improvement in the condition of patient, tolerance to the drug and side effects etc. were noted.

The main outcomes to be measured was menstrual blood loss by PBAC score, blood haemoglobin levels in $\mathrm{gm} / \mathrm{dl}$ and endometrial thickness in $\mathrm{mm}$, on 18-21 day of menstrual cycle by trans-vaginal sonography (TVS).

\begin{tabular}{|ll|}
\hline $\mathbf{1}$ point & For each lightly stained pad \\
$\mathbf{5}$ points & For each moderately stained pad \\
$\mathbf{2 0}$ pints & For each completely saturated pad \\
Tampons & \\
$\mathbf{1}$ point & For each lightly stained tampon \\
$\mathbf{5}$ points & For each moderately stained tampon \\
$\mathbf{2 0}$ pints & For each completely saturated tampon \\
Clots & \\
$\mathbf{1 p o i n t}$ & For each small clot (size of a rupee coin/smaller) \\
$\mathbf{5}$ point & For each larger clot (larger than a rupee coin)
\end{tabular}

Figure 1: different degrees of soiling of sanitary napkins and number and size of clots passed.

Pictorial blood loss assessment chart (PBAC) Higham et al was used to measure the menstrual blood loss (MBL). ${ }^{8}$ The women were taught to use only one variety of sanitary napkins which will show to have similar absorbent capacities. They had to record the number of 
napkins used each day and the degree of soiling of each pad used. Number and size of clots passed were also noted. Scores were assigned to different degrees of soiling of sanitary napkins and number and size of clots passed as per Figure 1.

A PBAC score of less than or equal to 100 was considered a normal menstrual blood loss. Score more than 100 was considered diagnostic of menorrhagia".

PBAC score, haemoglobin concentration and endometrial thickness were measured before the start of therapy and at end of 3 months i.e. after the completion of therapy.

A detailed menstrual history (number of days of menstruation, number of sanitary napkins used, passage of clots, dysmenorrhea) and physical examination was done at each visit. Any side effects observed were noted.

The subjective improvement of symptoms and acceptability of drugs were inquired from the patients in their own local language. Patients were asked for the improvement in fractions of a rupee coin. 4 annas improvement in one rupee was taken as mild improvement, 8 annas improvement in a rupee was taken as moderate improvement while 12 annas improvement in a rupee was taken as marked improvement.

\section{Statistical analysis}

Statistical parameters were used as Mean \pm standard Deviation and data were analysed using the paired $t$ test. The change in mean PBAC and endometrial thickness in two groups were compared using unpaired t-test. Statistical significance was taken at $\mathrm{p}$ value $\leq 0.05$.

\section{RESULTS}

Out of these 100 patients of DUB 9 were lost in follow up, 1 was diagnosed as endometrial T.B., 2 as atypical hyperplasia, and 2 as chronic endometritis on the basis of endometrial biopsy report, 2 patients had thyroid dysfunction and hence were excluded from the study.

In control group no significant reduction was seen in pretreatment and post-treatment PBAC score ( $\mathrm{P}$ value$0.1264)$ as well as in endometrial thickness ( $P$ value $0.7973)$ but definite improved haemoglobin status was seen $(\mathrm{P}$ value $<0.0001)$

In both ormeloxifene and $\mathrm{COC}$ group significant reduction in pre and post treatment PBAC score as well as endometrial thickness was seen along with significant increase in pre and post treatment haemoglobin status.

Table 1: Comparison of PBAC score pre and post treatment with ormeloxifene.

\begin{tabular}{|lllll|}
\hline PBAC & Mean & Number & Standard deviation & p-value \\
\hline Pre- treatment & 249.22 & 27 & 85.19 & $\mathbf{p}<\mathbf{0 . 0 0 0 1}$ \\
\hline Post treatment & 52.04 & 27 & 53.50 & $\mathbf{P}$ \\
\hline
\end{tabular}

Table 2: Comparison of endometrial thickness ( $\mathrm{mm})$ by TVS pre and post treatment with ormeloxifene.

\begin{tabular}{|llll|c|}
\hline Endometrial thickness $\mathrm{mm}$ ) & Mean & Number & Standard deviation & p-value \\
\hline Pre- treatment & 9.711 & 27 & 3.430 & $\mathbf{0}<\mathbf{0 . 0 0 0 1}$ \\
\hline Post treatment & 6.056 & 27 & 2.331 & $\mathbf{0}$ \\
\hline
\end{tabular}

Table 3: Comparison of haemoglobin (gm/dl) pre and post treatment with ormeloxifene.

\begin{tabular}{|llll|l|}
\hline Haemoglobin(gm/di) & Mean & Number & Standard deviation & p-value \\
\hline Pre- treatment & 9.374 & 27 & 0.969 & $\mathbf{p}<\mathbf{0 . 0 0 0 1}$ \\
\hline Post treatment & 10.589 & 27 & 0.877 & $\mathbf{p}$ \\
\hline
\end{tabular}

\section{Group B - DUB cases treated with prmeloxifene}

Out of 33 patients 4 left the treatment in between, two cases were dropped from the study as one of them was found to have Tubercular endometritis and other was found to have atypical hyperplasia on histopathological study. A total of 27 patients completed treatment with ormeloxifene for three months continuously.
It was observed that mean PBAC score reduced to 52.04 from 249.22 after 3 months of treatment with ormeloxifene. This $79.11 \%$ reduction in menstrual blood loss was found to be statistically significant $(\mathrm{p}<0.0001)$.

Endometrial thickness in millimeters was calculated by TVS in 27 number of patients treated with ormeloxifene prior to the therapy as well as after its completion. A significant reduction ( $\mathrm{p}$ value $<0.0001$ ) in endometrial 
thickness was seen after treatment with ormeloxifene; thereby decreasing the blood loss during menstruation.

When mean haemoglobin level was compared pre and post treatment with ormeloxifene, a rise from $9.374 \mathrm{gm} / \mathrm{dl}$ to $10.589 \mathrm{gm} / \mathrm{dl}$ was seen. Inspite of no iron therapy given along with ormeloxifene a significant improvement $(\mathrm{p}<0.0001)$ in anemia was seen in the subjects.
Group C: DUB cases treated with cyclic combined Oral Contraceptive Pills for three cycles (33 cases)

Out of 33 patients in Group C, one patient left the treatment in between, four patients were dropped from the study as two of them were diagnosed as chronic endometritis, one as atypical hyperplasia on histopathological study and one had thyroid dysfunction. A total of 28 patients were left in the group.

Table 4: Comparison of PBAC score pre and post treatment with combined oral contraceptive pills.

\begin{tabular}{|lllll|}
\hline PBAC score & Mean & Number & Standard deviation & p-value \\
\hline Pre- treatment & 217.50 & 28 & 62.94 & $\mathbf{0}<\mathbf{0 . 0 0 0 1}$ \\
\hline Post treatment & 94.04 & 28 & 57.45 & $\mathbf{0}$ \\
\hline
\end{tabular}

Table 5: Comparison of endometrial thickness ( $\mathrm{mm})$ by TVS pre and post treatment with combined oral contraceptive pills.

\begin{tabular}{|lllll|}
\hline Endometrial thickness $(\mathrm{mm})$ & Mean & Number & Standard deviation & p-value \\
\hline Pre- treatment & 10.032 & 28 & 2.895 & $\mathbf{p}<\mathbf{0 . 0 0 0 1}$ \\
\hline Post treatment & 7.064 & 28 & 1.857 & $\mathbf{0}$ \\
\hline
\end{tabular}

In this group too reduction in mean PBAC score was seen from 217.50 to 94.04 after completion of therapy with OCPs. This $56.76 \%$ reduction in blood loss was found to be statistically significant $(\mathrm{p}<0.0001)$.

Mean endometrial thickness prior to the treatment was observed to be $10.032 \mathrm{~mm}$ with standard deviation of 2.895 which reduced to $7.064 \mathrm{~mm}$ with standard deviation of 1.857. A significant reduction in endometrial thickness was thus seen after treatment with cyclical combined oral contraceptive pills, thereby reducing menstrual blood loss.

A rise in mean haemoglobin level from $8.921 \mathrm{gm} / \mathrm{dl}$ with standard deviation 1.271 to $10.007 \mathrm{gm} / \mathrm{dl}$ with standard deviation 1.378 was seen after three months treatment with combined oral contraceptive pills, in spite of no iron therapy being given along with it. This increase in haemoglobin level was found to be statistically significant $(\mathrm{p}<0.0001)$.

Table 6: Comparison of haemoglobin (gm/dl) pre and post treatment with combined oral contraceptive pills.

\begin{tabular}{|llll|l|}
\hline Haemoglobin(gm/dI) & Mean & Number & Standard deviation & p-value \\
\hline Pre- treatment & 8.921 & 28 & 1.271 & $\mathbf{0}<0.0001$ \\
\hline Post treatment & 10.007 & 28 & 1.378 & $\mathbf{0 . 0 0 1}$ \\
\hline
\end{tabular}

In both Group B and Group C there was significant change in all the three measured parameters i.e. PBAC score, endometrial thickness and hemoglobin concentration with three months treatment with respective drugs.

Although there was a reduction in mean PBAC score in both the groups compared, the mean change in PBAC score after the treatment with respective drugs was 197.19 in ormeloxifene group while only 123.46 in the subjects treated with OCPs. This mean change in PBAC

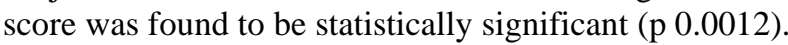

It was seen that mean change in the endometrial thickness measured in Group B (ormeloxifene) was $3.5 \mathrm{~mm}$ and $3.068 \mathrm{~mm}$ in Group C (OCPs). Reduction in endometrial thickness was also more in group $\mathrm{B}$ than group $\mathrm{C}$ but the

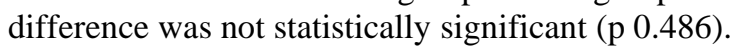

There was no major side effect with ormeloxifene. Amenorrhea was the main symptom accounting for 5 cases $(22.22 \%)$. Among these 5 women 4 were $\geq 40$ years and only 1 was < 40 years. Nausea vomiting $(11.11 \%)$ and headache $(7.4 \%)$ were other side effects but neither was significant enough to stop the therapy. 
The women were asked about the subjective improvement of symptoms. Majority (70.37\%) showed marked improvement in symptoms. Three women had no improvement in symptoms; however, there was no aggravation of symptoms in any woman. Ormeloxifene was acceptable to $88.88 \%$ women.

Table 7: Comparison of mean change in PBAC score in Group B and Group C.

\begin{tabular}{|llll|l|}
\hline Group & N & Mean change in PBAC score & Standard deviation & p-value \\
\hline B & 27 & 197.19 & 100.01 & 0.0012 \\
\hline C & 28 & 123.46 & 53.64 & \\
\hline
\end{tabular}

Table 8: Comparison of mean change in endometrial thickness ( $\mathrm{mm})$ in Group B and Group C.

\begin{tabular}{|c|c|c|c|c|}
\hline Group & $\mathbf{N}$ & Mean change in endometrial thickness & Standard deviation & p-value \\
\hline $\mathrm{B}$ & 27 & 3.507 & 2.473 & \multirow{2}{*}{0.486} \\
\hline $\mathrm{C}$ & 28 & 3.068 & 2.172 & \\
\hline
\end{tabular}

Only $32.14 \%$ patients did not experience any side effect with combined oral contraceptive pills. The main symptom was gastric upset seen in $21.42 \%$ of patients. Breast tenderness and weight gain was reported in $17.85 \%$ and $14.28 \%$ patients respectively.

With COC $35.71 \%$ showed marked improvement in symptoms, four patients $(14.28 \%)$ showed no improvement in symptoms while none had aggravation of symptoms.

\section{DISCUSSION}

The problem of dysfunctional uterine bleeding i.e. excessive or prolonged regular/ irregular menstrual bleeding in the absence of overt uterine pathology, endocrine or haematological disorder is a common reason for consultation in gynaecological outpatient department. DUB is disease of adolescent to perimenopausal aged women. Hence search for treatment of DUB suitable to all age groups of women is still continued. Although conservative surgery (i.e. endometrial ablation) is an alternative to hysterectomy, there continues to be a demand for alternative to surgery as a means of reducing menstrual blood loss because its cost is a limiting factor in developing countries so, for women with DUB who wish to retain fertility, pharmacological approaches are the only currently available options.

Long term daily oral drug treatment is restricted by poor compliance and unacceptable side-effects.

The role of levonorgestrel intrauterine system (LNG-IUS) in menorrhagia is well-established and is now considered to be the reference treatment in medical management but its cost limits its widespread use, especially in developing countries, such as India. ${ }^{9,10}$

Need of the hour for the treatment of DUB should be a designer drug which blocks the action of oestrogen on endometrium but not its beneficial actions on other tissues. Ormiloxifene is one such drug, categorized as "selective oestrogen receptor.

In our study we compared the reduction in blood loss after treatment with COC and ormeloxifene in patients of DUB.

In our study reduction in mean PBAC score and endometrial thickness pre and post treatment with ormeloxifene was significant, this was found consistent with other studies.

Similarly, reduction in mean PBAC score and endometrial thickness pre and post treatment with COC was also found significant, and consistent with various available studies.

No literature is available for comparison of the observations and results of treatment of the DUB with combined OCPs versus ormeloxifene. Presently we have conducted such study and on comparing the results of both the groups we found that patients taking ormeloxifene showed higher improvement in subjective symptoms like pads used and dysmenorrhoea than patients taking combined OCPs. $88.8 \%$ of patients responded to ormeloxifene with three months treatment and majority (70.37\%) out of them showed marked improvement; while $85.71 \%$ patients responded to combined OCPs but only $35.71 \%$ patients showed marked improvement.

On objective assessment, reduction in PBAC score in ormeloxifene group was $79.11 \%$ as compared to $56.76 \%$ with combined OCPs therapy. This is a significant difference (p-0.0012). Improvement in haemoglobin status was also more in ormeloxifene group as compared to combined OCP s group. (11.47\% versus $10.85 \%$ respectively).

Significant reduction in mean endometrial thickness was observed in both group B and C i.e. 3.057 $\pm 2.473 \mathrm{~mm}$ and 
$3.068 \pm 2.172 \mathrm{~mm}$ respectively. Though reduction in mean endometrial thickness was more in Ormeloxifene group as compared to Combined OCPs group but this was not a significant difference $(\mathrm{p}=0.486)$.

\section{CONCLUSION}

From above observations, inference is drawn that the ormeloxifene is more effective than only iron or combined oral contraceptive therapy in controlling the menstrual blood loss $(79.11 \%$ versus $58.57 \%)$.

Ormeloxifene is found significantly better than combined OCP in reduction of menstrual blood flow $(79.11 \%$ versus $56.76 \%$ ) in cases of DUB, also improvement in subjective symptoms was better with ormeloxifene than with combined OCP.

Reduction in mean endometrial thickness though found better in ormeloxifene group than in combined OCPs group but statistically it was not significant.

There were no side effects like weight gain or breast tenderness seen with patients who received ormeloxifene.

Ormeloxifene also had no side effects such as depression, mood changes, mastalgia and poor libido. It is also devoid of androgenic ill effects such as acne and hirsutism. Being a metabolically non-controversial agent, complications such as weight gain, hypertension, coagulation disorders, hyperglycaemia and abnormal lipid profile which are common with combined OCP do not occur.

More patient compliance was seen for ormeloxifene because of twice a week schedule as compared to daily dosing in combined OCP.

Better control of subjective symptoms like pads used per cycle and dysmenorrhoea was seen with ormeloxifene.

Ormeloxifene also offers perimenopausal bone and cardiovascular protection.

Ormeloxifene is also found oncologically protective to the breast and the endometrium.

Ormeloxifene being a better and safer nonsteroidal, convenient (60 mg twice a week dose) can also be prescribed to the women of all the ages in spite of having personal or family history of CAD, endometrial carcinoma, breast carcinoma, obesity, chronic renal diseases, hypertension and diabetes etc. History of these diseases make combined OCPs therapy for DUB cases - a contraindication.

Funding: No funding sources

Conflict of interest: None declared

Ethical approval: The study was approved by the Institutional Ethics Committee

\section{REFERENCES}

1. Crosignani PG, Rubin B. Dysfunctional uterine bleeding. Human Reprod. 1990;5:637-8.

2. Fraser IS. The dysfunctional uterus - dysmenorrhoea and dysfunctional uterine bleeding. In: Shearman RP, editor. Textbook of clinical reproductive endocrinology. Edinburgh: Churchill Livingstone; 1985:578-598.

3. Fraser IS, Hickey M, Song JY. A comparison of mechanisms underlying disturbances of bleeding caused by spontaneous dysfunctional uterine bleeding or hormonal contraception. Hum. Reprod. 1996;11(Suppl 2):165-78.

4. Fraser IS, Sungurtekin U. Defining menstrual disturbances. In: Maclean A, O'Brien PMS, editors. Study Group on Menstrual Disorders. Royal College of Obstetricians and Gynaecologists. 2000;141-152.

5. Livingstone M, Fraser IS. Mechanisms of abnormal uterine bleeding. Hum Reprod Update. 2002;8:60-7.

6. Patel SR, Sheth MS, Rawal MY. Dysfunctional uterine bleeding place for hysterectomy in its management. J Postgrad Med. 1986;32:150-3.

7. Sonoda, Barakat R, Richard. Screening and the prevention of gynecologic cancer: Endometrial cancer. Best practice and research. Clin Obstet Gynaecol. 2006;20:363-77.

8. Higham JM, O’ Brien PMS, Shaw RW. Assessment of menstrual blood loss using a pictorial chart. Br J Obstet Gynaecol. 1990;97:734-9.

9. Milsom I. The levonorgestrel releasing intra uterine system as an alternative to hysterectomy in perimenopausal women. Contra. 2007;75:S152S154.

10. Kriplani A, Singh BM, Lal S, Agarwal N. Efficacy, acceptability and side effects of the levonorgestrel intra uterine system for menorrhagia. Int J Gynaecol Obstet. 2007;97:190-4.

Cite this article as: Gupta A, Raj R. Ormeloxifene versus combined oral contraceptive pills to control blood loss in cases of dysfunctional uterine bleeding. Int J Reprod Contracept Obstet Gynecol 2019;8:4909-14. 